\title{
Curcuma longa aqueous extract: A potential solution for the prevention of corneal scarring as a result of pterygium surgical excision (Review)
}

\author{
GIANMARCO STATI ${ }^{1}$, SILVIA SANCILIO ${ }^{1}$, MARIANGELA BASILE $^{1}$, \\ ANTONIO ANGELINI ${ }^{1,2}$ and ROBERTA DI PIETRO ${ }^{1}$ \\ ${ }^{1}$ Department of Medicine and Ageing Sciences, ${ }^{2}$ Center for Advanced Studies and Technology, \\ d'Annunzio University of Chieti-Pescara, I-66100 Chieti, Italy
}

Received March 2, 2020; Accepted July 30, 2020

DOI: $10.3892 / \mathrm{ijmm} .2020 .4738$

\begin{abstract}
Curcumin has been used since ancient times as a treatment for a wide range of pathologies. For centuries, it has been considered to be an effective aid for common human diseases. Curcuma longa has been reported to possess various beneficial properties and actions, including anti-inflammatory, proapoptotic, antiangiogenic and cortisone-like actions. Pterygium is a degenerative disorder of the conjunctiva indicative of a strong inflammatory condition that requires surgical treatment, which often results in disfiguring sclerocorneal scars. The delay in the healing of superficial corneal wounds caused by topical administration of light-cortisone results in improved restoration of corneal functions and anatomy compared with physiological healing processes. The present review is focused on the medicinal properties of curcumin, the main component of Curcuma longa extract, in particular its strong cortisone-like effect, and its potential use for the prevention and treatment of sclerocorneal scars resulting from pterygium surgical excision.
\end{abstract}

\section{Contents}

1. Introduction

2. Pterygium and its treatment

3. Medicinal properties of Curcuma longa

4. Curcumin and the cortisone-like effect

5. Effect of curcumin on the healing of corneal damage

6. Potential use of Curcuma longa aqueous extract as a treatment of scars of the anterior segment of the eye

7. Safety of curcumin

Correspondence to: Dr Silvia Sancilio, Department of Medicine and Ageing Sciences, d'Annunzio University of Chieti-Pescara, Via dei Vestini 31, I-66100 Chieti, Italy

E-mail: s.sancilio@unich.it

Key words: Curcuma longa, pterygium, keratinocytes, sclerocorneal scar, corneal wound healing

\section{Introduction}

Curcuma longa is a perennial herb that belongs to the Zingiberaceae family (1). It is known by various synonyms, including turmeric and Indian saffron, and has been translated into a number of languages across the world; in Tibetan language it is known as Gaser, whereas in Swahili it is termed Manjano. It is primarily considered to be a coloring agent in the USA, whereas in India it has been used since ancient times as a spice and safe medical remedy, due to its reported beneficial effects in the treatment of dysentery, fever, infections, arthritis and colitis (2). The most notable active components of the herb for medicinal use are curcuminoids; diferuloyl methane represents $~ 90 \%$ of the curcuminoid content in turmeric, followed by demethoxycurcumin and bis-demethoxycurcmin (3-6). For centuries, Curcuma longa has been considered to be effective as a treatment for the common cold, urinary tract disease and liver disease, and as a blood purifier (7). Curcumin is extensively used in traditional and alternative medicines, such as Ayurveda, Unani, Siddha and Chinese medicine, for the management of various diseases and conditions, such as wounds, inflammation and cancer $(8,9)$. It was approved as a 'generally safe' compound by the Food and Drug Administration in the USA. In the last three decades, various studies have indicated that curcumin possesses antioxidant, anti-inflammatory, antiangiogenic, and wound-healing properties $(10,11)$. A number of reports indicate potential health benefits of curcumin in the treatment of anterior segment eye diseases $(12,13)$.

\section{Pterygium and its treatment}

Ocular pterygium is a typically bilateral pathology of the bulbar conjunctiva, generally located on the nasal side and, occasionally, even at the temporal side of the conjunctiva (14). It is characterized by an invasive growth of vascularized connective tissue along with the conjunctival epithelium, resulting in tissue remodeling, fibrovascular proliferation and inflammation (15). Pterygium keratinocytes are tumor-like transforming cells that share features with tumors, such as local invasion, metaplasia, inactivation of tumor suppressor genes and loss of heterozygosity (16). An epidemiological study demonstrated a strong 
association between pterygium and UV sunlight exposure, which may damage the DNA; DNA damage has been reported to initiate pterygium development (17). Due to the progressive increase of the ages of populations, the incidence of ophthalmic pterygium is predicted to increase. Despite its benign nature, if untreated, it can grow and invade the cornea, overcoming the corneoscleral junction, impairing visual function and occasionally leading to blindness (18). Although the pathogenesis of the disease is not completely understood, it has been reported that inflammation and fibrosis, angiogenesis and the destruction of the extracellular matrix are factors closely associated with the occurrence of pterygium (19).

At present, surgery is the only effective treatment for pterygium, although relapses are very common; with simple excision techniques, the risk of recurrence has been reported to be $>80 \%$ (20). The surgical operation consists of the detachment and removal of the pterygium head followed by conjunctival suture, leaving an ample portion of bare sclera or attaching the tissue up to the corneoscleral limbus; it may also be necessary to perform conjunctival reconstruction through the sliding of the tissue or even autologous transplant of the conjunctiva (21). Due to this type of procedure, complications such as infections, conjunctival cysts, or adherent scars limiting ocular movements and impairing visual function may occur (21). A second option for surgical excision of pterygium is the use of amniotic membrane graft, through which a part of the donor's amniotic membrane is fixed to the remaining limbus and bare sclera area after the excision of pterygium (22). The most reliable method is considered to be the use of conjunctival autografts, which involves the removal of the pterygium, essentially leaving an area of bare sclera that is closed by the movement of a free conjunctival transplant from another part of the ocular surface, usually from the superior-temporal part of ocular bulbous (23); however, even this latter method comes with potentially disfiguring corneal complications.

There is no clear-cut single treatment of choice for removing either a primary pterygium or recurrent pterygium; although there are several possible surgical methods (22), there is a high likelihood of sclerocorneal scarring as a result of surgical excision (24). If the scarring extends close to the visual axis, irregular astigmatism and reduced visual function may occur as a disabling complication of the surgery. Moreover, a pterygium that is being removed due to active growth near the visual axis is much more likely to result in some visual loss resulting from scarring near the line of vision (22). The risk is even more accentuated after removal of a recurrent pterygium. Furthermore, recurrences can on occasion be far more aggressive and serious than the original pterygium (25).

Associated with a far lower risk of recurrence is the use of adjunctive pharmacological therapy alongside surgical removal. There are four principal adjunctive therapies of interest: Intraoperative mitomycin; postoperative mitomycin; postoperative $\beta$-irradiation; and postoperative 5 -fluorouracil (5-FU) (26). Intraoperative and postoperative mitomycin are the most commonly used adjunctive treatments, with mitomycin applied at a dose of $0.2 \mathrm{mg} / \mathrm{ml}$ for $3 \mathrm{~min}$ during surgery, or for 14 days after pterygium removal, at the same concentration, once daily (27). The recurrence rate is reported to be acceptably low and commensurate with $\beta$-irradiation at $<10 \%$ (28). Nevertheless, there are numerous concerns regarding complica- tions, such as severe pain, corneal and scleral necrosis, and even scleral perforation. With 5-FU, potential complications include cornea opacity, conjunctivitis, sclera granuloma and conjunctiva necrosis (29). Although these complications have been reported rarely, they appear to be most frequently associated with the adjunctive therapies or topical chemotherapy, and may present as a late postoperative issue (26).

At present, there is still no pharmacological treatment of choice for sclerocorneal scarring; cortisone eye drops, which have not led to satisfactory outcomes, are the only existing palliatives. Our recent study reported a proapoptotic effect of Curcuma longa on human pterygium keratinocytes (13). Thus, it is hypothesized that curcumin may be an effective topical treatment capable of preventing corneal and scleral scars, and the frequent recurrences following surgical excision of pterygium.

\section{Medicinal properties of Curcuma longa}

Anti-inflammatory properties. It has been suggested that curcumin has a diverse range of molecular targets, supporting the hypothesis that it interacts with multiple cellular signaling pathways and modulates numerous biochemical-metabolic pathways. Both topical and oral administration of curcumin has been found to be as effective as cortisone for the treatment of pain and inflammation (30). Oral intake of Curcuma longa substantially reduces inflammatory swelling (4). Furthermore, curcumin is a highly pleiotropic molecule capable of interacting with numerous molecular targets and cell signaling pathways involved in inflammation, including NF- $\mathrm{KB}$, activated protein-1, STAT, peroxisome proliferator-activated receptor- $\gamma$ (PPAR- $\gamma$ ) and $\beta$-catenin (31). The expression and activation of regulatory proteins such as chemokines, interleukins (ILs), hematopoietic growth factors and transcription factors, which in turn inhibit cellular inflammatory responses and protect cells, has been also reported (31). Of note, Curcuma longa is able to inhibit the biosynthesis of prostanoids from arachidonic acid, and curcuminoids inhibit phospholipases, nitric oxide, elastase, hyaluronidase, collagenase, monocyte chemoattractant protein, interferon-inducible protein, tumor necrosis factor and IL-12 $(32,33)$. They also decrease prostaglandin, leukotriene and thromboxane biosynthesis via both cyclooxygenase (COX) and lipoxygenase pathways (34). COX-2 and inducible nitric oxide synthase inhibition by curcumin occur via suppression of NF- $\kappa B$ activation, which occurs by blocking the phosphorylation of I $\kappa B$ (35). Curcumin is an agonist of PPAR- $\gamma$, and its activation is associated with the downregulation of NF- $\kappa B$, which results in a reduction of a number of proinflammatory proteins, such as matrix metallopeptidase (MMP)-9 and MMP-2 (36), both of which play important roles in generating chemotactic stimuli such as vascular endothelial growth factor (VEGF) (37). Curcumin induces anti-inflammatory and proapoptotic effects that may serve beneficial roles in ocular disease (38-40). Furthermore, curcumin induces the downregulation of enzymes such as protein kinase $\mathrm{C}$, which mediates, among other functions, inflammation and tumor cell proliferation (41).

Proapoptotic action. Curcuma longa is able to induce apoptotic cell death in pterygium-derived human keratinocytes (13). Evidence suggests that the proapoptotic effects of curcumin are mediated through pro-oxidant pathways (42). Curcumin treatment 
leads to the production of reactive oxygen species (ROS) and changes in intracellular glutathione levels; curcumin-induced apoptosis can be inhibited by glutathione (43). Furthermore, the proapoptotic activity of curcumin can be also inhibited by superoxide dismutase and $\mathrm{N}$-acetylcysteine in leukemia cells (42). These findings indicate the involvement of superoxide radicals in the effects of curcumin. The mechanism via which curcumin mediates its pro-oxidant effects is related to mitochondria, which are the major source of ROS in the cell (43). However, it is possible that curcumin activates mitochondrial enzymes, and leads to the production of ROS, which are required for the apoptotic effects of curcumin (44). The generation of ROS induced by curcumin may occur via its interactions with thioredoxin system (45), composed of thioredoxin reductase (TrxR), thioredoxin (Trx), and NADPH, potentially leading to the production of ROS. Curcumin inhibits proliferation and induces apoptosis in cancer cells (46), with minimal effects noted on corresponding non-tumor cell lines. Keratinocytes affected by pterygium exhibit features similar to those of tumors, such as the inactivation of tumor suppressor genes (16), mismatch of the Bax:Bcl-2 homologous antagonist killer protein expression ratio and hypermethylation of the p16 gene promoter (47). These features suggest a possible neoplastic nature of the pathologic condition (48), indicating a basis for potential proapoptotic effects of Curcuma longa on these cancer-like cells (13).

Antiangiogenic properties. Angiogenesis is a strictly controlled physiological process regulated by a variety of endogenous angiogenic and angiostatic factors (49). The microvascular system appears capable of responding to physiological demands such as chronic inflammation and wounds with rapid capillary growth (50). VEGF is a prominent proangiogenic growth-promoting hormone, secreted in great quantities in response to hypoxia-inducible factors (51). VEGF upregulates the production of MMPs by endothelial cells in the limbal vascular plexus, stimulating blood vessel formation (52). MMPs and other proteolytic enzymes degrade the extracellular matrix and basement membrane, allowing vascular endothelial cells to enter the sub-epithelial and stromal spaces within the cornea (53). The concentration of VEGF significantly decreases following treatment with curcumin; the inhibitory effects on VEGF synthesis are dose-dependent, with the most potent effect achieved with $80 \mu \mathrm{mol} / 1$ curcumin (54). In addition to effects on VEGF synthesis, Curcumin exhibits direct antiangiogenic activity both in vitro and in vivo by inhibiting endothelial cell proliferation and corneal neovascularization mediated by fibroblast growth factor (FGF)-2 in a dose-dependent manner (54). Furthermore, curcumin is a strong agonist of PPAR- $\gamma$ and, according to in vitro and in vivo models, PPAR- $\gamma$ ligands exert antiangiogenic effects (55). Finally, curcumin specifically targets the PI3K/Akt/IкB kinase signaling axis, which consequently leads to the suppression of both NF- $\kappa \mathrm{B}$ and mTOR pathways, as well as concomitant downregulation of VEGF and activation of caspase pathways (56). These events result in the induction of apoptosis and the prevention of angiogenesis.

\section{Curcumin and the cortisone-like effect}

The effects of corticosteroids on the corneal epithelium are notable for a number of reasons. Corticosteroids are the most effective drugs for the non-specific suppression of inflammation (57). They prevent corneal neovascularization in clinical and experimental studies $(58,59)$, and are widely used in ophthalmology, but they may delay the healing of corneal stromal wounds $(60,61)$. In fact, the topical application of cortisones decreases the epithelial healing rates compared with a control group treated with placebo (62). It has been shown that the repeated application of $1.0 \%$ prednisolone and $0.1 \%$ dexamethasone may delay the epithelial wound healing of a superficial epithelium ulcer and markedly reduce the tensile strength of corneal wounds throughout the recovery process $(62,63)$. Unfortunately, the propensity of cortisone, topically administrated in the eye, to raise the intraocular pressure limits its use in the treatment of corneal scars.

Curcumin has been demonstrated to have a potent anti-inflammatory effect and to be as effective as cortisone in cases of chronic inflammation (64). It was observed that the aqueous extract of Curcuma longa induces a cortisone-like effect; if applied in the form of eye drops, it is effective in delaying the healing of superficial corneal wounds, with a notable difference in the rate of healing of the superficial corneal wounds when compared with artificial tear eye drops (65). More recently, the anti-inflammatory and analgesic effects of curcumin were attributed to a combination of several properties, namely inhibition of COX, 5-lipoxygenase and glutathione S-transferase (66). It is also notable that curcumin lowers the production of histamine, and increases and extends the action of cortisol, a natural human corticosteroid hormone capable of reducing inflammation and pain (67).

\section{Effect of curcumin on the healing of corneal damage}

Curcumin has been reported to promote corneal epithelial wound healing, as well as recovery of corneal function (68). A delay in wound healing due to the local application of Curcuma longa aqueous extract has been previously observed, occurring in a similar manner to the delayed healing induced by cortisone (69); this contrasts with skin wound healing, in relation to which Curcuma longa produces fast wound closure and a short wound healing time (70). It has been reported that the local application of cortisone to corneal wounds delays the rate of healing, reducing the tensile strength of the corneal surface during the healing process $(60,63,71)$. After the use of cortisone eye drops on the cornea surface, ulcer fluorescein staining disappeared after only 80 h (72). Normally, the basal cells of the corneal epithelium form an epithelial plug within $24 \mathrm{~h}$ capable of covering the corneal wound, thus restoring the epithelial continuity over the superficial portion of the wound (73). On the basis of studies involving staining the outlines of corneal wounds with fluorescein, it was observed that the fluorescein stain disappeared within $72 \mathrm{~h}$ in both superficial and penetrating corneal wounds when placebo eye drops, such as saline solution, were used (65); conversely, the healing of corneal wounds following application of Curcuma longa aqueous extract was clearly delayed, as the fluorescein stain did not disappear until 11 days after wound induction. Furthermore, the use of cortisone only resulted in the disappearance of wound fluorescein staining after $128 \mathrm{~h}$ (72). Taken together, tensile strength and corneal stretch during corneal wound healing appear to be substantially reduced by the local application of Curcuma longa aqueous extract in the 
form of eye drops, due to its cortisone-like, anti-inflammatory and wound healing effects, leading to the restitutio ad integrum of corneoscleral function. In addition, it has been reported that eye drops formed using an alcoholic extract did not notably delay the rate of healing of corneal wounds, indicating that only some water-soluble factors contained in Curcuma longa are responsible for the effect (65).

\section{Potential use of Curcuma longa aqueous extract as a treatment of scars of the anterior segment of the eye}

The primary corneal functions are transmission of incident light, refraction, maintenance of structure, and protection of intraocular structures from pathogens and trauma (74). The transmission and refraction of light through the cornea depends primarily on the transparency of the cornea, which in turn is due to the highly specialized ultrastructure (75). The corneal stroma is a layer rich in extracellular matrix mainly composed of collagen types I and $\mathrm{V}$, proteoglycan fibers, modified fibroblasts and keratocytes, the latter of which account for 2-3\% of the stroma volume (76). The transparency of the cornea is due to the collagen fibers arranged in a uniformly equidistant way, arranged in orthogonal lamellae (74). Proteoglycans also play an important role in shaping this unique structure; the leucine-rich proteoglycans present in the stroma are responsible for the precise arrangement of the stromal lamellae by adjusting the interfibrillar distance (77).

Ocular trauma that occurs during surgical pterygium excision often results in scarring and loss of corneal transparency (78). In the event of injury, growth factors play a determining role in stroma repair, as they regulate the organization of the extracellular matrix (ECM) (79). IL-1, transforming growth factor (TGF)- $\alpha$, TGF- $\beta$, FGF-2, insulin-like growth factor 2 , epidermal growth factor receptor and connective tissue growth factor, which are mainly produced in the stromal epithelium, tear film and macrophages, induce the production of extracellular matrix-stimulating keratocytes to restore the stromal structure, forming an ordered ECM or scar tissue, depending on their ratios (80). In the early stages of corneal wound healing, actin-containing myofibroblasts synthesize large quantities of collagen, hyaluronic acid and biglicans, and only small amounts of proteoglycan-containing keratin sulfate; this results in the formation of a disorganized and opaque ECM (81). Only in a subsequent phase do myofibroblasts transform into fibroblasts, which, along with keratocytes, synthesize keratan sulfates, collagen type I and collagen type $\mathrm{V}$, thus forming an organized and transparent ECM (82).

During the normal corneal wound healing process, the centripetal contraction movement of the wound edges facilitates the closure of the defect, and results in tensile shrinkage of the corneal epithelium and consequent scar development (83). Based on previously reported studies investigating the anterior segment of the eye $(84,85)$, the use of Curcuma longa aqueous extract to prevent disfiguring corneal scarring after surgical excision of pterygium may be a viable treatment option. The extract would be proposed to work by reducing tensile strength of the rapid healing that occurs physiologically after corneal wound scarring (86). Fast wound closure accelerates wound contraction and can exacerbate scar formation (87). It has already been reported in in vivo studies that a delay in the healing of superficial corneal wounds caused by topical administration of mild cortisone enables improved restoration of corneal function and anatomy compared with physiological healing $(88,89)$. The use of corticosteroids in the management of corneal scarring has been reported; continued topical use of loteprednol, a mild corticosteroid, for 6 weeks after surgery resulted in the disappearance of leucomatous scars (90). Unfortunately, long-term side-effects of ocular use of cortisone, such as increases in intraocular pressure, glaucoma and cataract, limit its use (91).

Corticosteroids act via the suppression of arachidonic acid formation by producing phospholipase A inhibitory proteins called lipocortins. They temporarily block the exudative phase of inflammation and modulate fibroblast formation during the tissue repair stage. In the acute phase of inflammation, corticosteroids decrease the permeability of capillaries and cellular exudation is reduced (92). Additional mechanisms, such as suppressing leukocyte motility and chemotaxis, and inhibiting inflammatory cytokines, contribute to their action (93). In an in vitro study, it was observed that curcumin inhibited human pterygium fibroblast proliferation in a dose- and time-dependent manner (11), potentially leading to reduced tensile strength during wound healing. A delay in wound healing processes allows improved rearrangement of corneal stroma and consequentially complete corneal transparency (94).

During wound healing, free radicals and ROS induce tissue damage and play a major role in the scarring process (95). Several antioxidants have been reported to suppress oxidative damage to these tissues, such as polyphenols, tocopherols and carotenoids (96). Curcumin is a natural phenol that possesses antioxidant activity, inhibiting hydrogen peroxide damage in human keratinocytes and fibroblasts, which may prevent oxidative damage and promote the healing process (97). Topical administration of curcumin was reported to improve all phases of wound repair, including collagen synthesis and maturation, wound contraction and re-epithelialization (69). The current evidence concerning curcumin supports its use in the field of ophthalmology. It is proposed that the topical use of Curcuma longa aqueous extract may be an effective approach to facilitate corneal scar healing, and that it is also a viable candidate to prevent pterygium relapse after surgical excision. Additionally, the absence of notable side effects of curcumin treatment in human subjects should also be considered (98). However, further studies may be required for assessing its complete utility.

\section{Safety of curcumin}

Curcumin appears to be extremely safe and well tolerated in humans, even at high doses. A dose-escalation trial indicated the maximum tolerated dose and safety of curcumin (99). Humans appear to be capable of tolerating high doses of curcumin without notable side effects (100). A phase I study found no adverse effects of curcumin ingestion for 3 months of doses up to $8,000 \mathrm{mg} / \mathrm{day}$ : A single dose standardized powder extract of curcumin was administered to 24 healthy volunteers, with the dose ranging from 500-12,000 mg; no curcumin was detected in the serum of subjects administered $500,1,000,2,000,4,000,6,000$ or $8,000 \mathrm{mg}$ curcumin, and only low levels were detected in 2 subjects administered with 10,000 or $12,000 \mathrm{mg}$ curcumin (101). Despite its well-known safety and efficacy, at present curcumin has not been applied 
as an ophthalmic therapeutic drug due to its low aqueous solubility (102). Regarding the major limitations of the medicinal use of curcumin, its poor water solubility, stability and bioavailability, there has been considerable progress, including the design of more stable and more potent derivatives, as well as delivery vehicles such as liposomes, microbeads or nanoparticles (103-105). However, as tear fluids wash off eye drops rapidly, topical corneal therapy based on curcumin is still considered a challenge (106).

\section{Acknowledgements}

Not applicable.

\section{Funding}

This review was supported by 2019 Research Advantage Funds from the Ministry of Education, University and Research, Rome, Italy.

\section{Availability of data and materials}

Not applicable.

\section{Authors' contributions}

All authors contributed to the conception of the study and performed literature searches. GS drafted the manuscript. RDP critically revised the manuscript. All authors read and approved the final manuscript.

\section{Ethics approval and consent to participate}

Not applicable.

\section{Patient consent for publication}

Not applicable.

\section{Competing interests}

The authors declare that they have no competing interests.

\section{References}

1. Ammon HP and Wahl MA: Pharmacology of Curcuma longa. Planta Med 57: 1-7, 1991.

2. Ruby AJ, Kuttan G, Babu KD, Rajasekharan KN and Kuttan R: Antitumor and oxidant activity of natural curcuminoids. Cancer Lett 94: 79-83, 1995.

3. Apisariyakul A, Vanittanakom $\mathrm{N}$ and Buddhasukh D: Antifungal activity of turmeric oil extracted from Curcuma longa (Zingiberaceae). J Ethnopharmacol 49: 163-169, 1995.

4. Asher GN, Corbett AH and Hawke RL: Common herbal dietary supplement-drug interactions. Am Fam Physician 96: 101-107, 2017.

5. Ammon HP, Safayhi H, Mack T and Sabieraj J: Mechanism of antiinflammatory actions of curcumine and boswellic acids. J Ethnopharmacol 38: 113-119, 1993.

6. Akram M, Shahab-Uddin, Afzal A, Khan U, Abdul H, Mohiuddin E and Asif M: Curcuma longa and curcumin: A review article. Rom J Biol Plant Biol 55: 65-70, 2010.

7. Chainani-Wu N: Safety and anti-inflammatory activity of curcumin: A component of tumeric (Curcuma longa). J Altern Complement Med 1: 161-168, 2003.
8. Singh S and Kher A: Biological effects of curcumin and its role in cancer chemoprevention and therapy. Anticancer Agents Med Chem 6: 259-270, 2006.

9. Rahmani AH, AlZohairy MA, Aly SM and Khan MA: Curcumin: A potential candidate in prevention of cancer via modulation of molecular pathways. Biomed Res Int 2014: 761608, 2014.

10. Maheshwari RK, Singh AK, Gaddipati J and Srimal RC: Multiple biological activities of curcumin: A short review. Life Sci 78: 2081-2087, 2006

11. Zhang M,Bian F, Wen C and Hao N: Inhibitory effect of curcumin on proliferation of human pterygium fibroblasts. J Huazhong Univ Sci Technolog Med Sci 27: 339-342, 2007.

12. Huynh TP, Mann SN and Mandal NA: Botanical compounds: Effects on major eye diseases. Evid Based Complement Alternat Med 2013: 549174, 2013.

13. Sancilio S, Di Staso S, Sebastiani S, Centurione L, Di Girolamo N, Ciancaglini M and Di Pietro R: Curcuma longa is able to induce apoptotic cell death of pterygium-derived human keratinocytes. Biomed Res Int 2017: 2956597, 2017.

14. Sudhalkar A: Fixation and its role in the causation, laterality and location of pterygium: A study in amblyopes and non-amblyopes. Eye (Lond) 26: 438-443, 2012.

15. Livezeanu C, Crăițoiu MM, Mănescu R, Mocanu C and Crăiţoiu S: Angiogenesis in the pathogenesis of pterygium. Rom J Morphol Embryol 52: 837-844, 2011.

16. Dos Reis GM, de P R Júnior A, E Silva KS, Rodrigues DA, Gomes MC, Martins JV, da Costa IR, Freitas GA and Moura KK: Pterygium in patients from Goiânia, Goiás, Brazil. Genet Mol Res 14: 6182-6188, 2015.

17. Lu CW, Hao JL, Yao L, Li HJ and Zhou DD: Efficacy of curcumin in inducing apoptosis and inhibiting the expression of VEGF in human pterygium fibroblasts. Int J Mol Med 39: 1149-1154, 2017.

18. Mauro J and Foster CS: Pterygia: Pathogenesis and the role of subconjunctival bevacizumab in treatment. Semin Ophthalmol 24: 130-134, 2009.

19. Ribatti D, Nico B, Perra MT, Maxia C, Piras F, Murtas D, Crivellato E and Sirigu P: Correlation between NGF/TrkA and microvascular density in human pterygium. Int J Exp Pathol 90: 615-620, 2009.

20. Clearfield E, Muthappan V, Wang X and Kuo IC: Conjunctival autograft for pterygium. Cochrane Database Syst Rev 2: CD011349, 2016.

21. Hacıoğlu D and Erdöl H: Developments and current approaches in the treatment of pterygium. Int Ophthalmol 37: 1073-1081, 2017.

22. Hirst LW: The treatment of pterygium. Surv Ophthalmol 48: 145-180, 2003.

23. Nuzzi R and Tridico F: How to minimize pterygium recurrence rates: Clinical perspectives. Clin Ophthalmol 12: 2347-2362, 2018.

24. Fries FN, Suffo S, Daas L, Seitz B, Fiorentzis M and Viestenz A: Tenonplasty for closing defects during sclerocorneal surgery-A brief review of its anatomy and clinical applications. Clin Anat 31: 72-76, 2018.

25. Jirásková $\mathrm{N}$ and Rozsíval $\mathrm{P}$ : Treatment for recurrent pterygium. Cesk Slov Oftalmol 64: 68-70, 2008 (In Czech).

26. Chu WK, Choi HL, Bhat AK and Jhanji V: Pterygium: New insights. Eye (Lond) 34: 1047-1050, 2020.

27. Yanyali AC, Talu H, Alp BN, Karabas L, Ay GM and Caglar Y: Intraoperative mitomycin $\mathrm{C}$ in the treatment of pterygium. Cornea 19: 471-473, 2000.

28. Guo Q, Li X, Cui MN, Liang Y, Li XP, Zhao J, Wei LN, Zhang XL and Quan XH: Low-dose Mitomycin C decreases the postoperative recurrence rate of pterygium by perturbing NLRP3 inflammatory signalling pathway and suppressing the expression of inflammatory factors. J Ophthalmol 2019: 9472782, 2019.

29. Hickey-Dwyer M and Wishart PK: Serious corneal complication of 5-fluorouracil. Br J Ophthalmol 77: 250-251, 1993.

30. Nosratzehi T, Arbabi-Kalati F, Hamishehkar H and Bagheri S: Comparison of the effects of curcumin mucoadhesive paste and local corticosteroid on the treatment of erosive oral lichen planus lesions. J Natl Med Assoc 110: 92-97, 2018.

31. Shishodia S, Singh T and Chaturvedi MM: Modulation of transcription factors by curcumin. Adv Exp Med Biol 595: 127-148, 2007.

32. Huang MT, Lysz T, Ferraro T, Abidi TF, Laskin JD and Conney AH: Inhibitory effects of curcumin on in vitro lipoxygenase and cyclooxygenase activities in mouse epidermis. Cancer Res 51: 813-819, 1991 . 
33. Zhang F, Altorki NK, Mestre JR, Subbaramaiah K and Dannenberg AJ: Curcumin inhibits cyclooxygenase-2 transcription in bile acid- and phorbol ester-treated human gastrointestinal epithelial cells. Carcinogenesis 20: 445-451, 1999.

34. Bundy R, Walker AF, Middleton RW and Booth J: Turmeric extract may improve irritable bowel syndrome symptomology in otherwise healthy adults: A pilot study. J Altern Complement Med 10: 1015-1018, 2004.

35. Surh YJ, Chun KS, Cha HH, Han SS, Keum YS, Park KK and Lee SS: Molecular mechanisms underlying chemopreventive activities of anti-inflammatory phytochemicals: Down-regulation of COX-2 and iNOS through suppression of NF-kappa B activation. Mutat Res 480-481: 243-268, 2001.

36. Cheng Y, Ping J and Liu C: Effect of curcumin on activity of matrix metalloproteinase 2, 9 and nuclear expression of RelA in rat hepatic stellate cells by activating peroxisome proliferator-activated receptor gamma signal. Zhongguo Zhong Xi Yi Jie He Za Zhi 27: 439-443, 2007 (In Chinese).

37. McCawley LJ and Matrisian LM: Matrix metalloproteinases: They're not just for matrix anymore! Curr Opin Cell Biol 13: 534-540, 2001.

38. Lal B, Kapoor AK, Asthana OP, Agrawal PK, Prasad R, Kumar P and Srimal RC: Efficacy of curcumin in the management of chronic anterior uveitis. Phytother Res 13: 318-322, 1999.

39. Allegri P, Mastromarino A and Neri P: Management of chronic anterior uveitis relapses: Efficacy of oral phospholipidic curcumin treatment. Long-term follow-up. Clin Ophthalmol 4 1201-1206, 2010

40. Vallée A and Lecarpentier Y: Curcumin and endometriosis. Int J Mol Sci 21: 2440, 2020.

41. Liu JY, Lin SJ and Lin JK: Inhibitory effects of curcumin on protein kinaseCactivityinducedby 12-O-tetradecanoyl-phorbol-13-acetate in NIH 3T3 cells. Carcinogenesis 14: 857-861, 1993.

42. Kuo ML, Huang TS and Lin JK: Curcumin, an antioxidant and anti-tumor promoter, induces apoptosis in human leukemia cells. Biochim Biophys Acta 1317: 95-100, 1996.

43. Woo JH, Kim YH, Choi YJ, Kim DG, Lee KS, Bae JH, Min DS, Chang JS, Jeong YJ, Lee YH, et al: Molecular mechanisms of curcumin-induced cytotoxicity: Induction of apoptosis through generation of reactive oxygen species, down-regulation of $\mathrm{Bcl}-\mathrm{XL}$ and IAP, the release of cytochrome $\mathrm{c}$ and inhibition of Akt. Carcinogenesis 24: 1199-1208, 2003.

44. Bhaumik S, Anjum R, Rangaraj N, Pardhasaradhi BV and Khar A: Curcumin mediated apoptosis in AK-5 tumor cells involves the production of reactive oxygen intermediates. FEBS Lett 456: 311-314, 1999.

45. Fang J, Lu J and Holmgren A: Thioredoxin reductase is irreversibly modified by curcumin: A novel molecular mechanism for its anticancer activity. J Biol Chem 280: 25284-25290, 2005.

46. Aggarwal S, Ichikawa H, Takada Y, Sandur SK, Shishodia S and Aggarwal BB: Curcumin (diferuloylmethane) down-regulates expression of cell proliferation and antiapoptotic and metastatic gene products through suppression of IkappaBalpha kinase and Akt activation. Mol Pharmacol 69: 195-206, 2006.

47. Lękawa-Ilczuk A, Antosz H, Rymgayłło-Jankowska B and Zarnowski T: Expression of double strand DNA breaks repair genes in pterygium. Ophthalmic Genet 32: 39-47, 2001.

48. Kau HC, Tsai CC, Lee CF, Kao SC, Hsu WM, Liu JH and Wei YH: Increased oxidative DNA damage, 8-hydroxydeoxy-guanosine, in human pterygium. Eye (Lond) 20: 826-831, 2006.

49. Henning RJ: Therapeutic angiogenesis: Angiogenic growth factors for ischemic heart disease. Future Cardiol 12: 585-599, 2016.

50. Folkman J and Klagsbrun M: Angiogenetic factors. Science 235: 442-447, 1987

51. Liu W, Sha X, Wen Y, Zhao W, Luo W and Hua Z: Effect of Avastin on the migration and invasion of pterygium fibroblasts. Eye Sci 29: 214-218, 2014.

52. Zhang J, Cao YJ, Li FY, Li J, Yao LB and Duan EK: Effects of fibronectin, VEGF and angiostatin on the expression of MMPs through different signaling pathways in the JEG-3 cells. Am J Reprod Immunol 50: 273-285, 2003.

53. Liacini A, Sylvester J, Li WQ and Zafarullah M: Inhibition of interleukin-1-stimulated MAP kinases, activating protein-1 (AP-1) and nuclear factor kappa B (NF-kappa B) transcription factors down-regulates matrix metalloproteinase gene expression in articulate chondrocytes. Matrix Biol 21: 251-262, 2002.

54. Kim SJ, Choi JS and Chung SK: The effect of curcumin on corneal neovascularization in rabbit eyes. Curr Eye Res 35: $274-280,2010$
55. Sarayba MA, Li L, Tungsiripat T, Liu NH, Sweet PM, Patel AJ, Osann KE, Chittiboyina A, Benson SC, Pershadsingh HA and Chuck RS: Inhibition of corneal neovascularization by a peroxisome proliferator-activated receptor-gamma ligand. Exp Eye Res 80: 435-442, 2005.

56. Sun ZJ, Chen G, Zhang W, Hu X, Liu Y, Zhou Q, Zhu LX and Zhao YF: Curcumin dually inhibits both mammalian target of rapamycin and nuclear factor- $\kappa \mathrm{B}$ pathways through a crossed phosphatidylinositol 3-kinase/Akt/IкB kinase complex signaling axis in adenoid cystic carcinoma. Mol Pharmacol 79: 106-118, 2011.

57. Araki-Sasaki K, Katsuta O, Mano H, Nagano T and Nakamura M: The effects of oral and topical corticosteroid in rabbit corneas. BMC Ophthalmol 16: 160, 2016.

58. Azimzade $\mathrm{Y}$, Hong $\mathrm{J}$ and Mashaghi A: Immunophysical analysis of corneal neovascularization: Mechanistic insights and implications for pharmacotherapy. Sci Rep 7: 12220, 2017.

59. Zemanová $\mathrm{M}$ and Matušková V: Benefits and negatives of corticosteroid therapy in corneal pathologies. Cesk Slov Oftalmol 73: 69-77, 2017.

60. Dahmana N, Mugnier T, Gabriel D, Kaltsatos V, Bertaim T, Behar-Cohen F, Gurny R and Kalia YN: Topical administration of spironolactone-loaded nanomicelles prevents glucocorticoid-induced delayed corneal wound healing in rabbits. Mol Pharm 15: 1192-1202, 2018.

61. Stepp MA, Zieske JD, Trinkaus-Randall V, Kyne BM, Pal-Ghosh S, Tadvalkar G and Pajoohesh-Ganji A: Wounding the cornea to learn how it heals. Exp Eye Res 121: 178-193, 2014.

62. Petroutsos G, Guimaraes R, Giraud JP and Pouliquen Y: Corticosteroids and corneal epithelial wound healing. Br J Ophthalmol 66: 705-708, 1982.

63. Kadmiel M, Janoshazi A, Xu X and Cidlowski JA: Glucocorticoid action in human corneal epithelial cells establishes roles for corticosteroids in wound healing and barrier function of the eye. Exp Eye Res 152: 10-33, 2016.

64. Kotha RR and Luthria DL: Curcumin: Biological, pharmaceutical, nutraceutical, and analytical aspects. Molecules 24: 2930, 2019.

65. Mehra KS, Mikuni I, Gupta U and Gode KD: Curcuma longa (Linn) drops in corneal wound healing. Tokai J Exp Clin Med 9: 27-31, 1984

66. Wu Y, Qin D, Yang $\mathrm{H}$ and Fu H: Evidence for the participation of acid-sensing ion channels (ASICs) in the antinociceptive effect of curcumin in a formalin-induced orofacial inflammatory model. Cell Mol Neurobiol 37: 635-642, 2017.

67. Enyeart JA, Liu H and Enyeart JJ: Curcumin inhibits bTREK-1 $\mathrm{K}^{+}$channels and stimulates cortisol secretion from adrenocortical cells. Biochem Biophys Res Commun 370: 623-628, 2008.

68. Guo C, Li M, Qi X, Lin G, Cui F, Li F and Wu X: Intranasal delivery of nanomicelle curcumin promotes corneal epithelial wound healing in streptozotocin-induced diabetic mice. Sci Rep 6: 29753, 2016.

69. Panchatcharam M, Miriyala S, Gayathri VS and Suguna L: Curcumin improves wound healing by modulating collagen and decreasing reactive oxygen species. Mol Cell Biochem 290: 87-96, 2006.

70. Dai X, Liu J,Zheng H, Wichmann J, Hopfner U, Sudhop S, Prein C, Shen Y, Günther H and Schilling A: Nano-formulated curcumin accelerates acute wound healing through Dkk-1-mediated fibroblast mobilization and MCP-1-mediated anti-inflammation. NPG Asia Mat 9: e368, 2017.

71. Beltrani VS, Barsanti FA and Bielory L: Effects of glucocorticosteroids on the skin and eye. Immunol Allergy Clin North Am 25: 557-580, 2005.

72. Mehra KS, Mikuni I and Kumar A: Effects of vit: A and cortisone on healing of corneal superficial wounds. Tokai J Exp Clin Med 7: 315-318, 1982.

73. Yamada $\mathrm{M}$ and Mashima $\mathrm{Y}$ : Changes in proliferation and differentiation of basal cells during wound healing of rabbit corneal epithelial abrasions. Nippon Ganka Gakkai Zasshi 99: 10-16, 1995 (In Japanese).

74. Sridhar MS: Anatomy of cornea and ocular surface. Indian J Ophthalmol 66: 190-194, 2018.

75. Ehlers N, Heegaard S, Hjortdal J, Ivarsen A, Nielsen K and Prause JU: Morphological evaluation of normal human corneal epithelium. Acta Ophthalmol 88: 858-861, 2010.

76. Del Monte DW and Kim T: Anatomy and physiology of the cornea. J Cataract Refract Surg 37: 588-598, 2011.

77. Hassell JR and Birk DE: The molecular basis of corneal transparency. Exp Eye Res 91: 326-335, 2010. 
78. Wilson SL, El Haj AJ and Yang Y: Control of scar tissue formation in the cornea: Strategies in clinical and corneal tissue engineering. J Funct Biomater 3: 642-687, 2012.

79. Liu XF, Hao JL, Xie T, Mukhtar NJ, Zhang W, Malik TH, Lu CW and Zhou DD: Curcumin, a potential therapeutic candidate for anterior segment eye diseases: A review. Front Pharmacol 8: 66 , 2017.

80. Yu FS, Yin J, Xu K and Huang J: Growth factors and corneal epithelial wound healing. Brain Res Bull 81: 229-235, 2010.

81. Georgakopoulos CD, Makri OE, Pagoulatos D and Karamanos NK: Expression and localization of glycosaminoglycans/proteoglycan in pterygium: An immunohistochemical study. Med Hypothesis Discov Innov Ophthalmol 8: 39-43, 2019.

82. Hayashi R, Ishikawa Y, Sasamoto Y, Katori R, Nomura N, Ichikawa T, Araki S, Soma T, Kawasaki S, Sekiguchi K, et al: Co-ordinated ocular development from human iPS cells and recovery of corneal function. Nature 531: 376-380, 2016.

83. Hackam DJ and Ford HR: Cellular, biochemical, and clinical aspects of wound healing. Surg Infect (Larchmt) 3 (Suppl 1): S23-S35, 2002.

84. Deljou A, Weingarten TN, Mahr MA, Sprung J and Martin DP: Postoperative corneal injuries: Incidence and risk factors. Anesth Analg 129: 737-742, 2019.

85. Nita M and Grzybowski A: The role of the reactive oxygen species and oxidative stress in the pathomechanism of the age-related ocular diseases and other pathologies of the anterior and posterior eye segments in adults. Oxid Med Cell Longev 2016: 3164734, 2016

86. Reinstein DZ, Archer TJ and Randleman JB: Mathematical model to compare the relative tensile strength of the cornea after PRK, LASIK, and small incision lenticule extraction. J Refract Surg 29: 454-460, 2013

87. Nedelec B, Shankowsky H, Scott PG, Ghahary A and Tredget EE: Myofibroblasts and apoptosis in human hypertrophic scars: The effect of interferon-alpha2b. Surgery 130: 798-808, 2001.

88. Meyer JC, Stulting RD, Thompson KP and Durrie DS: Late onset of corneal scar after excimer laser photorefractive keratectomy. Am J Ophthalmol 121: 529-539, 1996.

89. Sarchahi AA, Parizi AM, Eghtedar M and Keshavarz S: Effect of different treatment regimen with dexamethasone and acetylcysteine on corneal wound healing in rabbits. Iran J Med Sci 36: 188-195, 2001

90. Amon $\mathrm{M}$ and Busin $\mathrm{M}$ : Loteprednol etabonate ophthalmic suspension $0.5 \%$ : Efficacy and safety for postoperative anti-inflammatory use. Int Ophthalmol 32: 507-517, 2012.

91. Csorba A, Soproni A, Maneschg O, Nagy ZZ and Szamosi A: Application of corticosteroid eye drops for allergic eye diseases in children. Orv Hetil 160: 329-337, 2019.

92. Ramamoorthy S and Cidlowski JA: Corticosteroids: Mechanisms of action in health and disease. Rheum Dis Clin North Am 42 15-31, vii, 2016.
93. Cronstein BN, Kimmel SC, Levin RI, Martiniuk F and Weissmann G: A mechanism for the antiinflammatory effects of corticosteroids: The glucocorticoid receptor regulates leukocyte adhesion to endothelial cells and expression of endothelial-leukocyte adhesion molecule 1 and intercellular adhesion molecule 1. Proc Natl Acad Sci USA 89: 9991-9995, 1992.

94. Jagetia GC and Rajanikant GK: Role of curcumin, a naturally occurring phenolic compound of turmeric in accelerating the repair of excision wound, in mice whole-body exposed to various doses of gamma-radiation. J Surg Res 120: 127-138, 2004.

95. Ahmad A and Ahsan H: Biomarkers of inflammation and oxidative stress in ophthalmic disorders. J Immunoassay Immunochem 41: 257-271, 2020.

96. Amir Aslani B and Ghobadi S: Studies on oxidants and antioxidants with a brief glance at their relevance to the immune system. Life Sci 146: 163-173, 2016.

97. Kant V, Gopal A, Pathak NN, Kumar P, Tandan SK and Kumar D: Antioxidant and anti-inflammatory potential of curcumin accelerated the cutaneous wound healing in streptozotocin-induced diabetic rats. Int Immunopharmacol 20: 322-330, 2014.

98. Yen YH, Pu CM, Liu CW, Chen YC, Chen YC, Liang CJ, Hsieh JH, Huang HF and Chen YL: Curcumin accelerates cutaneous wound healing via multiple biological actions: The involvement of TNF- $\alpha$, MMP-9, $\alpha$-SMA, and collagen. Int Wound J 15: 605-617, 2018.

99. Ravindranath $\mathrm{V}$ and ChandrasekharaN: Metabolismof curcuminstudies with [3H] curcumin. Toxicology 22: 337-344, 1981.

100. Ramsewak RS, DeWitt DL and Nair MG: Cytotoxicity, antioxidant and anti-inflammatory activities of curcumins I-III from Curcuma longa. Phytomedicine 7: 303-308, 2000.

101. Cheng AL, Hsu CH, Lin JK, Hsu MM, Ho YF, Shen TS, Ko JY, Lin JT, Lin BR, Ming-Shiang W, et al: Phase I clinical trial of curcumin, a chemopreventive agent, in patients with high-risk or pre-malignant lesions. Anticancer Res 21: 2895-2900, 2001.

102. Anand P, Kunnumakkara AB, Newman RA and Aggarwal BB Bioavailability of curcumin: Problems and promises. Mol Pharm 4: 807-818, 2007.

103. Feng T, Wei Y, Lee RJ and Zhao L: Liposomal curcumin and its application in cancer. Int J Nanomedicine 12: 6027-6044, 2017.

104. Lee DY, Hou YC, Yang JS, Lin HY, Chang TY, Lee KH, Kuo SC and Hsieh MT: Synthesis, anticancer activity, and preliminary pharmacokinetic evaluation of 4,4-disubstituted curcuminoid 2,2-bis(Hydroxymethyl)Propionate derivatives. Molecules 25: 479,2020

105. Lin X, Shi Y, Yu S, Li S, Li W, Li M, Chen S, Wang Y and Cong M: Preparation of poloxamer188-b-PCL and study on in vitro radioprotection activity of curcumin-loaded nanoparticles. Front Chem 8: 212, 2020.

106. Joseph M, Trinh HM, Cholkar K, Pal D and Mitra AK: Recent perspectives on the delivery of biologics to back of the eye. Expert Opin Drug Deliv 14: 631-645, 2017. 